\title{
¿LA SOCIEDAD CIVIL COMO AGENTE DEMOCRATIZADOR? UNA APROXIMACIÓN DESDE LA TEORÍA POLÍTICA
}

\author{
Marcos Engelken-Jorge \\ Universidad del País Vasco - Euskal Herriko Unibertsitatea
}

Resumen: En los años ochenta del siglo pasado resurgió un concepto, el de sociedad civil, que nos ha acompañado hasta el presente en debates de teoría política. Este artículo se centrará en esta noción según ha sido concebida para explicar y, sobre todo, promover procesos de profundización democrática. Se repasarán las acepciones clásicas de este concepto y se expondrá el debate actual sobre este tema. Este repaso llevará a concluir que un concepto de sociedad civil en sentido lato, como el ofrecido por Pérez-Díaz, resulta deseable, pues (i) nos permite ahuyentar el fantasma de un socio-centrismo que nos conduce a conclusiones estériles para la intervención social y la reforma política y (ii) prescinde de acepciones más restringidas de sociedad civil sobre las que pocas conclusiones generalizables se pueden obtener.

Palabras clave: sociedad civil, profundización democrática, reforma política, teoría democrática contemporánea.

\section{Civil Society as an Agent of Democratization? A Political Theory Perspective}

Abstract: The notion of 'civil society' re-emerged in the 1980s, and it has been subjected to debate by political theorists since then. In this article, this concept is assessed from the point of view of its usefulness for explaining and, in particular, promoting processes of democratic deepening. The classical meanings of civil society, as well as ongoing debates on this notion, are reviewed. It is argued that a broad notion of civil society, such as the one advanced by Pérez-Díaz, is preferable to other more common alternatives, since (i) it avoids adopting a socio-centric approach, which is useless for designing and promoting strategies of social and political reform; and (ii) it dispenses with more restricted meanings of civil society, on which few general conclusions can be obtained.

Keywords: civil society, democratic deepening, political reform, contemporary democratic theory.

\section{Introducción}

Hace ya casi tres décadas, en los años ochenta del siglo pasado, resurgió un concepto, el de sociedad civil, que nos ha acompañado hasta el presente en debates de teoría política'. Cinco son los motivos que, con Helmut Dubiel (1994; 109), podemos citar para su reaparición. En primer lugar, su auge se debió a la resistencia anticomunista en los antiguos países satélites de la

\footnotetext{
${ }^{1}$ Echando un vistazo a la publicación de manuales, que ayudan a tomar la temperatura de los debates aún abiertos, hace apenas unos años salió a la luz para el público hispanohablante un Manual de Sociedad Civil y Movimientos Sociales (Ibarra, 2005). En el mundo anglosajón, por su parte, el Oxford Handbook of Political Theory también se ocupa del tema y dedica un capítulo a la discusión del concepto de sociedad civil (cf. Chambers y Kopstein, 2006).
} 
URSS. Los intelectuales polacos y húngaros creyeron hallar en esta noción el término que designaba tanto al sujeto que pondría fin a los Estados autoritarios socialistas, como a aquél que lideraría el tránsito hacia la democracia. La sociedad civil se trataba, por otra parte, de un término que se alejaba tanto de la retórica revolucionaria, como del esquema restauracionista. En segundo lugar, el éxito de la expresión se debió a la necesidad, por parte de las izquierdas occidentales, de encontrar un nuevo horizonte utópico. El término les ayudaba, en efecto, a dibujar uno. El tercer motivo que podemos alegar con Dubiel se vincula a la autocomprensión de los movimientos sociales. La noción de sociedad civil les permitía a éstos dar sentido a su propia acción. En cuarto lugar, el resurgir de la expresión hunde sus raíces en el esfuerzo por parte de la filosofía anglosajona, especialmente del "liberalismo activista", por reconsiderar el liberalismo político. Finalmente, citemos el papel desempeñado por la "retórica política" (Dubiel, 1994: 109). En este sentido, sociedad civil alude "a la tensión de perfectibilidad dentro de las democracias liberales" una vez que la "contraposición legitimadora" entre democracia liberal y socialismo totalitario había desaparecido (Ibíd.).

Aún hoy buena parte del debate en torno a este concepto se liga a los motivos precitados. La expresión sociedad civil se esgrime en proyectos de profundización democrática, constituye un hito para la auto-observación social (por parte de actores sociales significativos) y se emplea como herramienta analítica con la que dar cuenta, desde la vicaria "exterioridad" (i.e. "objetividad") académica, de procesos de transformación social y política. Observemos, sin embargo, que tal y como sucede con todos los grandes conceptos que estructuran nuestro debate político, mucho deben al pasado, pero mucho también han evolucionado. Actualmente no se suele admitir, por ejemplo, que sea lo mismo la "sociedad civil" bajo un régimen autoritario, que la sociedad civil en una democracia liberal (cf. Arato, 1996; Chambers y Kopstein, 2006: 366; Dubiel, 1994: 111-114; Dvořáková, 2008: 582). Los procesos sociales aludidos en cada caso distan mucho de ser aprehensibles bajo un mismo concepto.

Las siguientes páginas se centrarán en la noción de sociedad civil según ha sido concebida para explicar y promover procesos de profundización y consolidación en las democracias occidentales. En otros términos, será el potencial de la sociedad civil como agente democratizador y legitimador de la democracia lo que nos ocupe aquí. Para ello, recuperaremos inicialmente la tesis acerca de la dependencia de todo gran concepto de su pasado, por lo que, en lo que sigue, nos retrotraeremos varios siglos para comenzar el relato acerca de la sociedad civil. Posteriormente, pasaremos a exponer parte de su actual polisemia. En todo caso, se puede adelantar una conclusión que años ha ya fue apuntada por Foley y Edwards (1996: 42): en el debate actual, el concepto de sociedad civil "parece adoptar las propiedades de un gas"; se expande o se contrae según el caso de estudio que en cada momento se tenga delante. Lo que sigue, por tanto, es un repaso a una serie de visiones heterogéneas, pero significativas de la sociedad civil. De ellas deduciremos, al final, algunas conclusiones. 


\section{Tres Perspectivas "Clásicas" del Concepto de Sociedad Civil}

Siguiendo a Fernando Vallespín (1996), podríamos comenzar distinguiendo tres grandes perspectivas desde las que contemplar la sociedad civil. De un lado, la que el politólogo madrileño asocia a la figura de John Locke y la "Ilustración escocesa" (Vallespín, 1996: 42). Desde este punto de vista, la sociedad es observada como anterior al Estado. Sus dinámicas y procesos de formación son concebidos como enteramente autónomos con respecto a los canales estatales. La "sociedad cívica" (civic society), desde esta óptica, sería equivalente a la "sociedad económica" (economic society), y la opinión pública constituiría el elemento que permitiría "a la comunidad reconocerse como tal en una esfera de mutua y libre interacción" (Ibíd.).

En el otro extremo del espectro, Vallespín sitúa el modelo que liga a la figura de Montesquieu y, sobre todo, de Tocqueville. Según esta perspectiva, la sociedad no puede ser definida con independencia de su constitución política. En el caso de Montesquieu, son los cuerpos intermedios, en el de Tocqueville, un vibrante tejido asociativo, amén de una democracia local activa y determinadas orientaciones civiles y religiosas ("hábitos del corazón"), los factores que evitan un excesivo repliegue hacia lo privado. Por el contrario, es precisamente este mundo asociativo el que se constituya "en la misma infraestructura de la política" (Vallespín, 1996: 43).

Entre estos dos modelos, Vallespín (1996: 43) sitúa la noción de sociedad civil de Hegel. En ella se reconoce, de un lado, la autonomía del ámbito social, que abarca también al sistema económico; del otro, empero, se le niega su autosuficiencia y se la declara en dependencia última del Estado.

La exposición de estas tres visiones encierra al menos dos virtudes. De un lado, expone las líneas directrices con las que aún hoy se sigue pensando la sociedad civil. Estado, economía y sociedad son los tres aspectos que cada perspectiva contemporánea articula de modos diferentes, otorgándoles matices diversos, trazando fronteras distintas entre los mismos y deduciendo consecuencias dispares. A estos tres aspectos habría que añadirles, ocasionalmente, la noción de "civilidad", que en algunos casos viene por simple añadidura (sería un epíteto asociado ya sea a la sociedad, a la economía o al Estado) y, en otros, constituye un elemento central para acotar qué es exactamente eso que llamamos sociedad civil. Por otro lado, estos tres enfoques ponen de relieve la multiplicidad de formas que, en lo más básico del planteamiento, caracteriza al debate actual. La sociedad civil es pensada esencialmente al margen del Estado (la perspectiva de Locke y de la llustración escocesa); es pensada como parte del Estado o como soporte del mismo (el modelo que se deriva de Montesquieu y de Tocqueville); o, justo al contrario, el Estado es presentado como soporte de la sociedad (Hegel).

No obstante, el debate contemporáneo ha añadido nuevos matices y problemas a esta estructura tríadica fundamental. Quizás por ello sea más útil abordar la situación actual a partir de una versión simplificada de dicha estructura. Si tomamos como referencia uno de los elementos precitados, el Estado, podemos referirnos a nociones de sociedad civil centradas en el Estado, y a otras que lo hacen en torno a la sociedad (Vallespín, 1996: 45). 


\section{Acepciones Contemporáneas del Concepto de Sociedad Civil}

\section{La Sociedad Civil como Estado}

En lo referente a las primeras, no son éstas precisamente abundantes en la actualidad. Al menos no, en el sentido que se quiere dar aquí a esta idea, la de "centradas en el Estado"2. Como representante destacado de este tipo de conceptos de sociedad civil, es decir, de los que se centran en el Estado, podríamos citar a Víctor Pérez-Díaz (1995). Para él, "las sociedades civiles históricas, reales, han sido siempre naciones específicas" (Pérez-Díaz, 1995: 81). La noción de sociedad civil trata de aprehender, por tanto, una experiencia histórica. Alude a un núcleo de instituciones socioeconómicas y políticas que, conectadas a determinadas disposiciones culturales, han caracterizado a ciertas sociedades del Atlántico Norte durante los últimos siglos. Dicho núcleo institucional ha consistido en una particular combinación de arreglos políticos y socioeconómicos: un gobierno limitado y obligado a rendir cuentas (accountable), que opera bajo el imperio de la ley (rule of law), una economía de mercado (lo cual implica un régimen de propiedad privada), una variedad de asociaciones libres y voluntarias (políticas, económicas, sociales y culturales) y una esfera de debate público libre. Una sociedad civil es, de acuerdo a PérezDíaz (1995: 81-82), una particular combinación de "asociación civil" (civil association) y de "asociación como empresa" (association as enterprise) ${ }^{3}$, esto es, de asociación orientada al interés general, abstracto y altruista, y de asociación en pos de un interés y objetivo común. Significa esto, entonces, que la sociedad civil combina en el plano de los valores morales que fomenta 0 permite intereses egoístas y espacios de acción privados, de un lado, e intereses comunes y vínculos de solidaridad, co-responsabilidad y de copertenencia, del otro (Pérez-Díaz, 1995: 82-83). Tal combinación de valores no se trataría, de ningún modo, de una síntesis en la que las tensiones hubiesen sido ya superadas, sino que la habilidad de la sociedad civil estribaría en encontrar un precario y siempre difícil equilibrio entre ambos grupos de valores y actitudes.

Si bien esta noción propuesta por Pérez-Díaz resulta ciertamente particular dentro de la plétora de definiciones que encontramos actualmente, no está por ello exenta de virtudes. Tal concepción de sociedad civil facilita, por una parte, el diálogo entre nuestra situación presente y la tradición liberal clásica; al tiempo que se nos provee de un concepto que subraya el carácter relacional de la sociedad civil: se trata de un juego de interacciones, abierto e indeterminado, entre elementos heterogéneos que trata de dejar a un lado la esperanza de encontrar un único centro fundacional o alguna suerte de actor histórico privilegiado (Pérez-Díaz, 1995: 98-99).

\footnotetext{
${ }^{2}$ Esta expresión, la de "centradas en el Estado", se interpreta aquí de forma ligeramente distinta a la que propone Vallespín. A nuestro juicio, esta reinterpretación es capaz de trazar una frontera algo más nítida entre ambas categorías de nuestra tipología de partida.

${ }^{3}$ Como se habrá deducido ya, los términos los ha tomado Pérez-Díaz de Michael Oakeshott.
} 


\section{Conceptos de Sociedad Civil Centrados en la Sociedad}

En lo referido a los conceptos de sociedad civil centrados en la sociedad, suelen provenir éstos de perspectivas preocupadas no sólo por definir el contenido de la sociedad civil, sino también (en algunos casos habría que decir sobre todo) sus fronteras con respecto a otros ámbitos igualmente relevantes; típicamente, el Estado. En el trazo de dichos límites se asume, en la actualidad, que tanto aspectos más propiamente sociológicos, como otros de naturaleza más bien legal deben ser considerados. Pues estos últimos terminan por actuar sobre los primeros (cf. Arato, 1996; Chambers y Kopstein, 2006: 366; Dubiel, 1994: 111-114; Dvořáková, 2008: 582). Dibujadas estas líneas divisorias, es decir, la que separa al Estado de la sociedad civil y la que hace lo propio entre regímenes autoritarios y liberales, en virtud de la desigual frontera legal que en unos y otros se dibuja entre Estado y sociedad, las perspectivas contemporáneas discrepan en la concepción que tienen de las relaciones entre Estado y sociedad civil. Así, por ejemplo, John Keane (1988: 19) pretende expresamente pensar la sociedad civil contra el Estado. Precisamente frente a esto John A. Hall (1995: 16) nos advierte del error de imaginar a la sociedad civil como opuesta a aquél. En efecto, dadas las repercusiones sociológicas que acarrea un determinado marco legal (liberal), no deberíamos suponer que los dos elementos precitados se encuentren enfrentados. Más bien, nos dice Hall, la sociedad civil requiere del Estado -y en este sentido se complementan y no se oponen- "como protección y para garantizar ciertas condiciones sociales básicas" (Ibíd.).

Con el fin de ordenar el debate contemporáneo entre todas las concepciones de sociedad civil centradas en la sociedad, una estrategia más fructífera que la de diferenciar según el criterio de "enfrentamiento con / complementariedad al Estado", que -como hemos visto- es conceptualmente erróneo, es la de agruparlas en las siguientes dos categorías: "sociedad civil en apoyo del Estado" y "sociedad civil en diálogo con el Estado" (cf. Chambers y Kopstein, 2006) ${ }^{4}$. No definen, como se habrá deducido, enfoques mutuamente excluyentes ni pretenden constituir una tipología exhaustiva. Simplemente, tratan de introducir un punto de orden dentro de la plétora de conceptos de sociedad civil "centrados en la sociedad". Como veremos, tanto en las perspectivas que se preocupan por la "sociedad civil en apoyo del Estado", como en las que lo hacen por su "diálogo con el Estado", se dan cita el enfrentamiento y la complementariedad con éste.

\footnotetext{
${ }^{4}$ Podríamos añadir una tercera categoría: "sociedad civil en asociación con el Estado" (Cf. Chambers y Kopstein, 2006: 374-375). La misma hace alusión a las nuevas formas de gobernanza y de descentralización política, ya sea para reducir la burocratización del Estado; por un genuino interés en promover los valores democráticos; para acercar la Administración Pública a la ciudadanía y acrecentar la legitimidad de sus decisiones; para evitar formas de gestión paternalistas y fomentar, por el contrario, la autorregulación; o para mejorar la calidad de los servicios públicos. Sin embargo, desde esta perspectiva lo que se plantea es un tipo de relación con el Estado, no tanto un nuevo contenido de la sociedad civil. Dado, por tanto, que esta perspectiva poco añade a la definición positiva del (contenido del) concepto de sociedad civil, prescindiremos, por ahora, de ella.
} 


\section{La Sociedad Civil en Apoyo del Estado}

El enfoque de la sociedad civil en apoyo del Estado asume un punto de vista neo-tocquevilleano, que enlaza con el debate acerca del capital social y de las asociaciones como escuelas de democracia. Se trataría, para estos autores, de un argumento análogo al de la mano invisible, pero aplicado a la vida asociativa. Si bien Tocqueville no hablaba tanto de sociedad civil como de asociacionismo, sus reflexiones pueden ser traídas a colación sin violentar demasiado sus argumentos.

Para él, "[l]os sentimientos y las ideas no se renuevan, el corazón no se engrandece, ni el espíritu humano se desarrolla, sino por la acción recíproca de unos hombres sobre otros. (...) y esto sólo las asociaciones pueden lograrlo." (Tocqueville, 1840: 142). Como sostendrá más adelante, "[e]ntre las leyes que rigen las sociedades humanas, hay una que parece la más precisa y clara. Para que los hombres conserven su civilización, o la adquieran, es preciso que la práctica asociativa se desarrolle y se perfeccione en la misma proporción en que aumenta la igualdad en las condiciones sociales." (Tocqueville, 1840: 144). Es decir, en la misma medida en que avanza el proceso de individualización y de atomización (cf. Tocqueville, 1840: 133). En suma, las asociaciones protegen frente al egoísmo y el aislamiento que emerge del mercado, al tiempo que se constituyen, como se citó más arriba, "en la misma infraestructura de la política" (Vallespín, 1996: 43). Amplían lealtades, fomentan virtudes y alumbran ideas nuevas. Robert Putnam (1993) es el heredero más conocido de esta tradición ${ }^{5}$.

Dentro de esta categoría de "sociedad civil en apoyo del Estado", pero en diálogo crítico con este enfoque neo-tocquevilleano, podríamos situar un grupo de autores cuyo pensamiento enfatiza sobre todo el pluralismo de la sociedad civil y, con él, una perspectiva más contextualista. Para ellos, por decirlo brevemente, la sociedad civil actúa (o puede hacerlo) en apoyo del Estado; pero nunca de un modo tan límpido como el sugerido por Tocqueville.

Atendamos, en primer lugar, a la perspectiva de Nancy L. Rosenblum (1994). Su argumento presupone una premisa que, en otro contexto, es desarrollada con mayor claridad por Göran Ahrne (1998). De acuerdo a este sociólogo, las cualidades de la sociedad civil no pueden exceder a las de sus unidades constitutivas; a saber, las organizaciones. En este sentido, éstas tienden a ser más bien inciviles (uncivi), en la medida en que precisan de formas de exclusión y de relaciones asimétricas entre los seres humanos (cf. Ahrne, 1998: 93). La sociedad civil, por tanto, no debería ser concebida -según Ahrnecomo un dechado de virtudes. Pero si no son paladines de la civilidad, tampoco suele ocurrir que estén frontalmente reñidas con ésta. El valor de la sociedad civil -se desprende de este argumento- estriba en su pluralidad. Rosenblum parte, en efecto, de esta preconcepción pluralista de la sociedad civil y añade a esta imagen la siguiente tesis: "no existe un único uso moral del pluralismo"

\footnotetext{
${ }^{5}$ El pensamiento de Putnam aqueja, no obstante, una cierta ambivalencia. A ratos, de resonancias "clásicas" y adherido a una determinada comprensión ética de la vida (véase, en especial, Putnam, 2003: 87-91); en otros, se nos presenta como un pensamiento claramente teñido por la teoría de la elección racional, al margen, por tanto, de toda retórica acerca de las virtudes y la civilidad (cf. Boix y Posner, 2000: 162-162).
} 
(Rosenblum, 1994: 546). Idealmente, sus "funciones" son atemperar la orientación por el interés egoísta y miope, integrar en redes sociales a personas desconectadas de las mismas e, inversamente, relajar el control exacerbado que comunidades tendencialmente totalitarias puedan ejercer sobre sus miembros. Son, evidentemente, "funciones" que coexisten en tensión, cuando no en oposición abierta. Por tal motivo, la autora, sin negar el potencial de la sociedad civil para actuar "en apoyo" del Estado, nos arenga a adoptar una actitud algo más escéptica y, sobre todo, a conceder mayor atención al contexto. No nos debería interesar tanto la estructura en sí de la sociedad civil, su valor en abstracto, sino las dinámicas que, en efecto, alimenta en contextos precisos. Cualquier otra generalización sería apresurada.

Para Michael Walzer (1990), otro autor destacado que puede ser incluido dentro de esta categoría, la noción de sociedad civil alude tanto al espacio de asociacionismo no coercitivo, como a las redes que dan contenido a dicho espacio. La sociedad civil se definiría, en fin, como un espacio de espacios (setting of settings; Walzer, 1990: 98). Esto es, como un entorno que posibilita que diferentes concepciones éticas, i.e. ligadas a una determinada concepción de la vida buena, sean llevadas a la práctica y compitan entre sí. Por tanto, la sociedad civil no constituye, al menos en principio, la encarnación de un proyecto ético autónomo, sino que se nos revela, más banalmente, como el escenario (vacío) que debe dar cabida al pluralismo contemporáneo (y, a la vez, como ese mismo pluralismo).

Para Walzer (1990: 103) el Estado se situaría frente a la sociedad civil, en una situación paradójica: representa un actor entre otros en medio de tal pluralismo y actúa, a la vez, como el agente que enmarca a la propia sociedad civil. De este modo, el valor de ésta radicaría en dos "funciones", cuyo desempeño satisfactorio no viene, empero, garantizado. De un lado, debería controlar e incidir sobre el poder estatal, es decir, la sociedad civil se situaría frente al Estado; y del otro, promocionar ciudadanos cuya altura de miras fuese más allá de ellos mismos y de sus compañeros. Que se preocupasen, en fin, por la comunidad política, es decir, el Estado, pues garantiza la institucionalización de la sociedad civil en tanto que espacio. Ésta actuaría, en suma, en apoyo del Estado.

Jeffrey C. Alexander (1993; 1997) también parte de presupuestos pluralistas, pero les concederá un nuevo enfoque. Para el sociólogo, las formas relativamente espontáneas de socialidad resultan ambiguas y no pueden ser apresuradamente identificadas como fuentes de civilidad, como harían tendencialmente Cohen y Arato (cf. infra). Sociedad civil no equivaldría, automáticamente, a altruismo y orientación al bien general; pero tampoco a lo contrario. La atraviesa, más bien, una indeleble ambigüedad, cuya necesidad puede ser lógicamente explicada -según Alexander (1993)-. Y esta explicación se hallaría justamente en que todo discurso acerca del Bien, la Razón o lo Razonable, gérmenes de civilidad, debe necesariamente postular conceptos opuestos: el Mal, lo Irracional o lo Irrazonable, siempre prestos a ser atribuidos a algún otro grupo social y a justificar, por tanto, su exclusión. La tensión entre lo cívico (universalista, incluyente) y lo incívico (particularista, excluyente) se hallaría, en fin, inscrita desde siempre en el seno de la sociedad civil. 
Posteriormente, Alexander (1997) enfocaría esta cuestión desde otro ángulo, aunque tratando de conservar aún lo que considera como la "paradoja de la sociedad civil"; esto es, su ambigüedad consustancial. Considera que, para ser analíticamente fructífera, la noción de sociedad civil debería referirse, exclusivamente, a una esfera específica de la sociedad; precisamente, aquélla que se nos aparece como un espacio de solidaridad ciudadana situado bajo el paraguas de una identidad colectiva compartida, esto es, de un Nosotros. En tanto que fundamento unificador del demos y promotor de la orientación por el bien común, la sociedad civil así concebida actuaría en apoyo del Estado, es decir, de la comunidad política considerada en su conjunto.

Habría que considerar, además, lo siguiente. La sociedad civil constituiría para Alexander- una esfera social entre otras, tales que la religiosa, familiar y científica, que se situaría a caballo entre la Gemeinschaft y la Gesellschaft, aunando tanto solidaridad y cohesión, como pluralidad, contestación e individualidad. Por supuesto, Alexander se muestra consciente de la tensión que existe entre la particularidad de toda identidad colectiva, necesaria para generar solidaridad y cohesión, y la abstracción de los valores universalistas que deben informarla, si ha de acoger la diferencia y la autonomía individual. Por definición, ambos polos coexistirían en tensión, informándose mutuamente. Constituye esto, precisamente, la "paradoja de la sociedad civil".

En todo caso, sin entrar a discutir el acierto de una aproximación como ésta, conviene ahora subrayar la principal aportación del sociólogo norteamericano. A saber, definir a la sociedad civil por su contenido (no exento de ambigüedad, es cierto), para de este modo ganar un concepto de sociedad civil que, por distinguirla de esferas articuladas de acuerdo a otras lógicas (el intercambio económico, el parentesco, la producción de conocimiento etc.), sea apta para el trabajo analítico. En otros términos, el tratamiento que Alexander realiza del pluralismo sigue una doble vía: de un lado, lo integra en el concepto de sociedad civil en la forma de una ambigüedad que le es inherente y que nos priva, por tanto, de valoraciones simples y unidireccionales; del otro -y aquí radica lo verdaderamente novedoso- trata de acotar un espacio dentro del pluralismo de lo social que, si bien no es enteramente homogéneo y se encuentra libre de tensiones, sí se encuentra regido, al menos, por lógicas que lo diferencian no sólo del Estado y del mercado, como viene siendo habitual, sino también de otras esferas sociales (la familia, la religión o la ciencia, por ejemplo) animadas supuestamente por otras dinámicas.

\section{La Sociedad Civil en Diálogo con el Estado}

Finalmente, entre los enfoques que observan la sociedad civil "en diálogo" con el Estado deberíamos destacar las aportaciones de Jean L. Cohen y Andrew Arato (1992), de un lado, y Jürgen Habermas (1992), del otro. Para los primeros, la sociedad civil sería una esfera de interacción entre la economía y el Estado, compuesta tanto por la esfera íntima (especialmente la familiar), el tejido asociativo (sobre todo asociaciones voluntarias), movimientos sociales y las diversas formas de comunicación pública (Cohen y Arato, 1992: ix). Los autores matizan que con el término sociedad civil no se están refiriendo a todo tipo de relaciones sociales fuera del Estado y de la economía. Distinguen entre 
sociedad civil, sociedad política, que engloba a partidos políticos, organizaciones políticas y "públicos políticos" (en especial, los parlamentos), y sociedad económica, que alude a organizaciones de producción y distribución, generalmente firmas, cooperativas, asociaciones etc. Para Cohen y Arato (1992: ix), la sociedad política y la sociedad económica surgen de la sociedad civil, comparten con ésta algunas de sus formas de organización y comunicación, y encuentran su institucionalización a través de derechos, especialmente políticos y de propiedad. Sin embargo, los actores de estas dos esferas se ven directamente envueltos en el poder estatal y en la producción económica, que tratan de controlar y gestionar. Esto significa -de acuerdo a estos dos autores (Ibíd.)- que los actores de estas dos esferas no pueden permitirse la libertad de subordinar los criterios económicos e instrumentales a los procesos de integración normativa y de comunicación abierta que caracterizarían a la sociedad civil. Supuestamente, de acuerdo a Cohen y Arato (1992: ix-x), el papel político de la sociedad civil no se encaminaría a la conquista del poder estatal, sino a su influencia. De manera similar ocurriría con el rol económico de la sociedad civil, es decir, ésta no trataría de controlar la economía, sino de influenciar su curso. En ambos casos, la sociedad política y la sociedad económica son contempladas como mediadoras entre la sociedad civil, de un lado, y el Estado y la economía, del otro.

Este modelo consigue que se manifieste una ambigüedad teóricamente fructífera. En efecto, para Cohen y Arato la supervivencia de la sociedad civil requiere, al menos en el largo plazo, de su "institucionalización" (Cohen y Arato, 1992: ix) 0 , en otros términos, de una tal estructura legal y del reconocimiento de determinados derechos básicos que permitan, a la postre, diferenciar a la sociedad civil del Estado y, cuando menos "tendencialmente", de la economía (Cohen y Arato, 1992: 346). Por este motivo, la sociedad civil no queda simplemente equiparada a la categoría de mundo de la vida, es decir, a aquellos puntos del entramado social en los que impera la integración lingüísticamente mediada (Habermas, 1981: 169-215). Se refiere, más concretamente, a las "estructuras de socialización, asociaciones y formas organizadas de comunicación dentro del mundo de la vida, en tanto que institucionalizadas o en proceso de institucionalización" (Cohen y Arato, 1992: $\mathrm{x}$ ). Asimismo, lo anterior implica también que la sociedad civil no se encuentra, necesariamente, opuesta a la economía y al Estado. Puede estarlo, al menos parcialmente, lo cual ocurrirá, sobre todo, cuando estos dos ámbitos, Estado y economía, consigan aislar sus procesos de decisión de la presión ejercida desde la sociedad civil (Cohen y Arato, 1992: x-xi).

La noción de sociedad civil en Cohen y Arato (1992: 18-19) está pensada como elemento crucial para el mantenimiento de una vida democrática. La sociedad civil no se orienta hacia la esfera privada, sino que lo hace, activamente, hacia la pública. Sin embargo, al contrario que los "demócratas radicales" (Cohen y Arato, 1992: 19), los teóricos norteamericanos no conciben un demos unificado y volcado, idealmente, sobre la vida pública, sino que insertan los criterios normativos de los teóricos de la participación en sociedades estructuralmente diferenciadas. En este rol de la sociedad civil como sustento de la democracia, conceden a los movimientos sociales un papel privilegiado (Cohen y Arato, 1992: 19-20). La propuesta de Cohen y Arato trata, por tanto, de conjugar los derechos liberales con los requerimientos democráticos de participación. Si 
bien ambos principios coexisten en tensión, los autores consideran que pueden ser remitidos a un mismo modelo teórico normativo, el de la ética del discurso, acuñado por Habermas (Cohen y Arato, 1992: 20-21).

Del filósofo alemán, Cohen y Arato asumen, además, su tesis acerca de la colonización sistémica del mundo de la vida. Recordemos brevemente que, para Habermas (1981: 429-527), el mundo de la vida se encuentra asediado por los imperativos que emanan de estructuras abstractas (el Estado y la economía) e integradas funcionalmente, esto es, al margen de procesos conscientes e intencionales (es decir, "lingüísticamente mediados") por parte de los actores sociales. El valor que Cohen y Arato atribuyen a la sociedad civil radica, entonces, en su capacidad para defender el mundo de la vida de los imperativos sistémicos que la economía y la burocracia estatal introducen en él; sin que esto suponga, por otra parte, renunciar a la autonomía (relativa) de estas esferas (sociedad civil, economía y Estado). Defender el mundo de la vida, además, sin caer en propuestas neoconservadoras:

"Apelaciones a la familia, la tradición o la comunidad pueden fomentar el fundamentalismo destructivo de falsas comunidades, tan fácilmente manipuladas desde arriba, a no ser que los logros del liberalismo (el principio de derechos [principle of rights -i.e. el derecho a tener derechos]), la democracia (el principio de la participación y el discurso [discourse -i.e. la deliberación colectiva]) y la justicia (una precondición de la solidaridad) sean defendidos en primer lugar y, posteriormente, complementados con nuevas formas democráticas e igualitarias de asociación en el seno de la sociedad civil" (Cohen y Arato, 1992: 24).

Cohen y Arato, en suma, dibujan un escenario que trata de capturar las complejas relaciones que existen entre diversos órdenes de la vida social y política. Reconocen la dependencia de la sociedad civil respecto de la regulación estatal; la importancia de la diferenciación funcional para las sociedades modernas (es decir, el valor de la descentralización y autonomización relativa de la economía, así como de la autonomización también parcial del Estado); pero también los peligros asociados a ésta: excesiva autonomización del Estado y de la esfera económica y, más aún, colonización del mundo de la vida por parte de estas dos instancias. Lo que tratan de alcanzar estos teóricos políticos es un difícil equilibrio entre estos diversos elementos y para tal fin dibujan la noción de sociedad civil que aquí se ha presentado con trazos gruesos: una sociedad civil que depende del Estado, pero que también es capaz de oponerse a él; que defiende el mundo de la vida, sin solaparse por entero con él; que trata de preservar ciertos aspectos del proceso de modernización, pero que aspira a corregir otros; y que es potencialmente capaz de ejercer influencia sobre el Estado y la economía a través, principalmente, de la esfera pública y de formas de acción colectiva no violentas, sino encaminadas, ante todo, a llamar la atención sobre ciertos problemas y popularizar nuevas semánticas y narrativas.

La principal aportación de perspectivas como la de Cohen y Arato estriba en que logra que apartemos parcialmente la mirada de las instituciones públicas y contemplemos la vida política y el proyecto democrático como cuestiones que en gran medida dependen del sustrato asociativo y comunicativo de nuestras 
sociedades (al respecto, véase también Rödel, 1996), e incluso de ámbitos privados como las relaciones familiares. Sería en este complejo entramado de relaciones entre sociedad civil, Estado, sociedad política, economía y sociedad económica en la que, de acuerdo a Cohen y Arato, deberíamos contemplar, a riesgo de caer en simplificaciones excesivas, los principales hitos de nuestra vida política y social: la integración (normativa, afectiva y funcional) de nuestras sociedades, la extensión real de derechos, la fuerza normativa de éstos (que, en tanto arraigan en procesos comunicativos, difieren de modelos como el del derecho positivo y el derecho natural); amén de buscar en aquel entramado de relaciones entre la sociedad civil, el Estado y el mercado los resortes y las fuerzas para el cambio social y político.

Finalmente, la obra de Habermas (1992) nos presenta un concepto de sociedad civil que alude a agrupaciones (Zusammenschlüsse), movimientos sociales, organizaciones y asociaciones de carácter voluntario y de naturaleza no estatal ni económica, que anclan las estructuras de comunicación de la esfera pública en los componentes sociales del mundo de la vida (Habermas, 1992: 443-4). Significa esto, por tanto, que la sociedad civil recoge, condensa y da expresión pública a los problemas (sociales, en tanto que compartidos) que la ciudadanía experimenta en su vida cotidiana. Al igual que Cohen y Arato, Habermas ve en la sociedad civil un espacio normativamente privilegiado, pues en ella cristalizan en mayor medida que en otros ámbitos sociales los principios normativos ínsitos a nuestra praxis comunicativa ${ }^{6}$ : la sociedad civil -a juicio del filósofo alemán- es esencialmente igualitaria, abierta y se orienta al interés general (lbíd.).

El valor de la sociedad civil en la vida política queda condicionado, en el pensamiento de Habermas, por el modelo con el que piensa el sistema político. Se trata de un modelo de exclusas ordenado en torno a un eje centro / periferia y caracterizado por dos métodos de abordar y resolver los problemas (zwei Arten der Problemverarbeitung; Habermas, 1992: 430). En el centro se sitúa el gobierno y la administración, la justicia, el parlamento, partidos políticos, sistema electoral etc. Se trata, por tanto, de un centro poliárquico, con competencias específicas y formalizadas. En la periferia, por su parte, encontramos a los Abnehemer, es decir, clientes, actores sociales orientados a los outputs del sistema, y a los Zulieferer o proveedores, que se orientan hacia los inputs en el sistema. La relevancia que, desde el punto de vista de la deontología democrática, cabe atribuir a la sociedad civil radica en su función de "proveedora" del sistema. En la sociedad civil se gesta la comunicación informal que luego deberá llegar a la opinión pública, dominada por los medios de comunicación de masas. Contribuye a lanzar temas a la palestra, propone soluciones, aduce argumentos, vierte críticas, defiende valores etc. Para adquirir legitimidad, el sistema político debe ser capaz de atender a estos flujos comunicativos y de traducirlos en políticas públicas (Habermas, 1992: 432).

La sociedad civil actúa en el modelo habermasiano, así como en el propuesto por Cohen y Arato, tanto de manera defensiva como ofensiva, funciones que se conjugan típicamente en los movimientos sociales. Actúa ofensivamente, cuando persigue un determinado proyecto hegemónico: plantea problemas,

\footnotetext{
${ }^{6}$ Acerca de los "principios ínsitos a nuestra praxis comunicativa", una referencia sucinta y esclarecedora: Habermas (1996).
} 
soluciones, perspectivas, valores etc. Defensivamente, cuando lucha a favor del mantenimiento y profundización de la propia sociedad civil (Habermas, 1992: 447-8).

Por otra parte, el filósofo alemán es contundente a la hora de marcar los límites de lo que podríamos denominar la "funcionalidad" de la sociedad civil. Ésta no es, de ningún modo, un nuevo sujeto histórico que pueda o deba controlar a la sociedad en su conjunto ni que nos ofrezca, en exclusiva, la vara de medida con la que determinar la legitimidad o ilegitimidad de los outputs políticos (Habermas, 1992: 450). Al igual que para Cohen y Arato, para Habermas una sociedad compleja tiene necesidad de diferenciarse en subsistemas, razón por la cual la sociedad civil no debería ignorar la existencia de diversos subsistemas sociales con intereses, criterios de valoración y normas de funcionamiento diversos.

Una consideración especialmente interesante que nos ofrece el filósofo alemán es la diferenciación entre dos "circuitos" (Kreisläufe) de poder. El que se ha esbozado hasta ahora, que sería el circuito "oficial", y el rutinario (Habermas, 1992: 433). El primero no sólo se ve cotidianamente desmentido por la observación empírica, sino que requiere, en su propio diseño conceptual, de una contra-dinámica que lo libere de la sobrecarga de complejidad, que por otro lado no es siempre políticamente relevante. En el ciclo rutinario, el sistema político tendría a aislarse de lo social y de sus demandas; las políticas públicas no emergerían del ágora, sino de los despachos de funcionarios públicos y de burócratas de partido; que no estarían interesados en el interés general, sino más bien en asuntos partidistas o de pura promoción profesional; sería, finalmente, el marketing político el que sustituyese a la práctica deliberativa en la sociedad civil y el espacio público.

Con esto, Habermas introduce un nuevo elemento, más realista, pero también menos utópico y con menor potencial crítico, en el debate en torno a la sociedad civil. El modelo rutinario cuenta con virtudes innegables, siendo la primera de ellas su capacidad para resolver asuntos cotidianos sin sobrecargar el sistema político. Reconociendo esto, el filósofo replantea las exigencias normativas que se proyectan sobre dicho sistema. Lo fundamental sería, ahora, si la sociedad civil es capaz, cuando las condiciones o la relevancia del tema tratado así lo aconsejan, de transmutar el ciclo de funcionamiento rutinario en el oficial (Habermas, 1992: 434). Una expectativa, por otra parte, que el propio autor estima problemática (Ibíd.), que requiere de ciertos elementos (a saber, una determinada cultura política liberal y un determinado tejido asociativo) que no se encuentran sencillamente a disposición de la ciudadanía (Habermas, 1992: 435), sino que presuponen pautas culturales gestadas en el largo plazo. Es por esto que incluso esta versión algo menos exigente de la sociedad civil que la presentada por Cohen y Arato ha sido cuestionada por presuponer, quizás, "una excesiva anticipación de una sociedad ya reconciliada" (Vallespín, 1997: 223). 


\section{La Utilidad del Concepto de Sociedad Civil para el Proyecto de Profundización Democrática}

Las discrepancias en torno a la noción de sociedad civil afectan tanto a la determinación de su referente, como a la precisión de los atributos de dicho referente, pese a que los autores mencionados hasta ahora consideren ambos aspectos conjuntamente. Las cuestiones que estructuran el debate son, por tanto, básicamente dos: la que se interroga por los atributos de un referente (¿qué podemos predicar del mismo?) y la que se cuestiona, a la luz de dichos atributos, por la idoneidad de singularizar un determinado objeto o referente (¿aquello que predicamos del mismo justifica que seleccionemos y singularicemos una determinada parcela de la realidad y que nos refiramos a ella con un único término, como si constituyese, en efecto, una unidad?). Los autores vistos hasta ahora juegan con estos dos aspectos y los combinan y aprecian de modos diferentes, obteniendo, a la postre, resultados distintos.

Por centrarnos ahora en el polo del referente, nos fijábamos más arriba en un concepto de sociedad civil, el de Pérez-Díaz, que aludía a un tipo determinado de configuración socioeconómica y política. El sociólogo español nombraba con el término sociedad civil un núcleo institucional, históricamente identificable, que -a su juicio- era capaz de producir efectos característicos. Ésta no es, ciertamente, la concepción de sociedad civil más extendida actualmente, pero la perspectiva que abre no deja por ello de ser interesante. El hecho mismo de que Pérez-Díaz haya optado por construir el concepto de sociedad civil con esta amplitud ya pone de manifiesto las enormes dificultades con las que se enfrentarán los otros conceptos, que pretenden identificar un espacio más acotado y específico dentro de estas configuraciones socioeconómicas y políticas, y reservar el término "sociedad civil" para designar dicho espacio. La aproximación de Pérez-Díaz pone de manifiesto que la imbricación de elementos de la sociedad civil (en sentido restringido; i.e. la noción propugnada por otros autores) con aspectos supuestamente externos a la misma (el Estado, la economía) es tal, que no resulta descabellado operar con un concepto amplio de la misma; es decir, tomando como referente ciertas configuraciones socioeconómicas y políticas en su conjunto.

En el extremo opuesto encontrábamos a Alexander, el autor que más restringe el referente de la sociedad civil. Recordemos que, con esta noción, el sociólogo norteamericano designa una esfera específica de la sociedad. Una esfera, por lo demás, que debe caracterizarse por ciertas lógicas sociales que la distinguen no sólo del Estado y la economía, sino también de otros ámbitos sociales: el científico, familiar o el religioso, por ejemplo. Trazar las fronteras entre tales esferas resulta, cuando menos, un esfuerzo titánico, aunque en buena medida necesario, si no queremos caer en la imprecisión conceptual. No obstante, llevada hasta el extremo la propuesta de Alexander, se corre el riesgo de fragmentar en exceso nuestra mirada sobre lo social y hacernos perder de vista las intricadas interrelaciones entre diversas esferas, como bien subrayaba la propuesta de Pérez-Díaz. Por el contrario, si se la persiguiese simplemente de un modo laxo, la propuesta de Alexander no sería, bien mirada, muy diferente de la que plantea la mayoría de los restantes autores. 
Las demás aproximaciones repasadas en este texto se mueven entre aquellos dos polos marcados por Pérez-Díaz y Alexander. Si bien existen importantes diferencias entre ellas, se puede afirmar con bastante seguridad que todas operan, con más o menos matices, dentro del marco triádico Estado / sociedad civil / economía, designando la sociedad civil una realidad plural y pluralista que englobaría el tejido asociativo, movimientos sociales y redes más o menos informales de comunicación.

En lo concerniente a los atributos de la sociedad civil, especialmente en tanto que agente democratizador, habíamos observado que su rol para la profundización democrática es concebido habitualmente con lentes neotocquevilleanas o desde la teoría de la acción comunicativa. En lo que se refiere a la primera perspectiva, debemos admitir que los argumentos propuestos por Putnam, uno de sus representantes más destacados, no son baladíes ni podemos ignorar la evidencia empírica que aporta este autor. Sin embargo, el debate en torno al capital social (véase especialmente Newton, 2001) y a los usos del pluralismo apuntan a que una mayor precisión teórica es necesaria. Resulta sintomático, en este sentido, que tanto Walzer como Alexander hablen de una "paradoja de la sociedad civil", si bien refiriéndose a cuestiones diferentes. Del mismo modo, no parece que podamos pasar por alto la tesis central de Rosenblum; recordemos, que "no existe un único uso moral del pluralismo" (Rosenblum, 1994: 546). Así las cosas, la precaución aconseja no tomar automáticamente a la sociedad civil como beneficiosa para la democracia, en tanto que generadora de confianza interpersonal y de virtudes cívicas como el interés por la política, la inclinación a participar en los asuntos públicos o la predisposición a definir el propio interés considerando el interés de los restantes conciudadanos (Putnam, 1993: 87-90) ${ }^{7}$. Todo apunta a que no deberíamos desdeñar la conclusión de Rosenblum: no nos debería interesar tanto el valor en abstracto de la sociedad civil, cuanto sus efectos en contextos determinados. Citemos a este respecto la reflexión de Foley y Edwards (1999: 155): "La dificultad de alcanzar una paz duradera en Belfast y Beirut debería disuadirnos de que la "densidad asociativa" tiene el mismo significado en todos los contextos sociales y políticos" (de modo similar, pero formulado más recientemente, Edwards, 2004: 42-49).

Por su parte, desde posiciones influenciadas por la teoría de la acción comunicativa, la sociedad civil tiende a ser concebida como un espacio normativamente privilegiado, en tanto que en él cristalizarían (de forma aproximada, al menos) los presupuestos normativos ínsitos a nuestra praxis comunicativa; es decir, horizontalidad, inclusividad, coordinación de la acción a través del principio del mejor argumento etc. (Unos supuestos, por otro lado, que no todos los autores comparten. Recuérdese a este respecto la crítica de Alexander a Cohen y Arato). Dada esta posición normativamente privilegiada, la sociedad civil debería actuar como agente defensor del mundo de la vida frente a la excesiva expansión de la economía y la burocratización estatal y, más aún, como agente capaz de influir sobre (no sólo de defenderse de) la economía y el Estado. No obstante, no deja de resultar llamativo que un

\footnotetext{
${ }^{7}$ Recuérdese, no obstante, lo afirmado más arriba acerca de la ambigüedad que aqueja al pensamiento de Putnam. Éste oscila entre una comprensión republicana de la democracia y la teoría de la elección racional. Sólo en el seno de la primera cobran pleno sentido las referencias realizadas a las virtudes cívicas.
} 
proyecto como éste haya sido revisado a la baja. Para Habermas recordémoslo- el funcionamiento rutinario del sistema político no carece de virtudes, por lo que redefine el papel de la sociedad civil como una suerte de agente que, hablando desde la deontología democrática, debería ser capaz de influir sobre el centro del sistema político; pero -a su juicio- sólo sería necesario ejercer tal capacidad de influencia en momentos excepcionales. No obstante, como bien sugería Vallespín, una sociedad civil con esta capacidad es ya una sociedad civil fuerte; y una sociedad civil fuerte, como reconocía Habermas, es dependiente de elementos que no se encuentran sencillamente a disposición de la ciudadanía, sino que, por el contrario, presuponen pautas culturales gestadas en el largo plazo.

Resulta sumamente interesante este punto de la argumentación, pues recuerda a una de las críticas centrales vertidas contra el concepto de capital social. Para Margaret Levi (1996) una aproximación como la de Putnam resulta sociocéntrica y descuida el papel que las instituciones públicas puedan tener en la conservación y producción de capital social. En efecto, la sociedad civil vista desde el prisma del capital social puede, a lo sumo, contar con poder explicativo, pero carece de mucha utilidad si lo que se pretende es implementar alguna estrategia de profundización democrática, debido a la perspectiva temporal, que abarca procesos de varios siglos, con la que se concibe la creación de capital social (Putnam, 1993: 121-162). Así las cosas, las nociones de sociedad civil presentadas tanto desde una óptica neo-tocquevilleana como desde la teoría de la acción comunicativa nos conducen a la tesis de que existen algo así como un "círculo virtuoso" y otro "vicioso" con capacidad para reforzar o socavar nuestras democracias (Putnam, 177); concibiendo tales círculos como auto-generativos y, en el corto y medio plazo, como poco susceptibles de ser alterados por nuestra intervención deliberada. De acuerdo a ambas perspectivas, la sociedad civil sería, en efecto, un agente o, cuando menos, un potencial agente democratizador; pero uno que opera, en buena medida, al margen de posibles intervenciones estratégicas.

No dar por fracasado el concepto de sociedad civil como noción desde la que pensar y fomentar la consolidación y profundización de nuestras democracias requeriría, por tanto, escapar de esquemas de pensamiento socio-céntricos, que -como hemos visto- nos conducen a conclusiones poco prácticas para la intervención estratégica sobre la realidad social. Requeriría, en suma, recuperar el interés por las instituciones políticas y el impacto de éstas sobre el asociacionismo y el fomento de diversas pautas culturales beneficiosas para la democracia. A esto nos lleva la lógica de la argumentación: un concepto de sociedad civil en sentido lato, como el ofrecido por Pérez-Díaz, nos facilita concebir, ya desde el inicio, las intricadas relaciones que existen entre instituciones, pautas culturales y tejido asociativo; y paralelamente, nos permite ahuyentar el fantasma de un socio-centrismo que nos conduce a conclusiones estériles para la intervención social consciente. Finalmente, nos fuerza a prescindir de categorías como la de sociedad civil en sentido restringido (i.e. concebida, con más o menos matices, en el marco de la tríada Estado / sociedad civil / economía), sobre la que, como hemos visto, pocas conclusiones generalizables podemos obtener; y en su lugar, operar con otra serie de conceptos que quizás -sólo al final lo sabremos- resulten 
analíticamente más precisos y más útiles para la intervención estratégica sobre la realidad social.

\section{Agradecimientos}

El autor agradece al Vicerrectorado de Investigación de la Universidad del País Vasco/ Euskal Herriko Unibertsitatea la concesión de una Ayuda para la Especialización de Investigadores Doctores, sin la cual no hubiese sido posible este trabajo.

\section{Referencias}

(1998) AHRNE, Göran, "Civil Society and Uncivil Organizations". En Jeffrey C. Alexander (ed.), Real Civil Societies. Dilemmas of Institutionalization, Sage, Londres, pp 84-95

(1993) ALEXANDER, Jeffrey C., "The Return to Civil Society", Contemporary Sociology, XXII, 6, ISSN 0094-3061, pp 797-803

(1997) ALEXANDER, Jeffrey C., "The Paradoxes of Civil Society", International Sociology, XII, 2, ISSN 0268-5809, pp 115-133

(1996) ARATO, Andrew, "Emergencia, declive y reconstrucción del concepto de sociedad civil. Pautas para análisis futuros", Isegoría, 13, ISSN 1130-2097, pp $5-17$

(2000) BOIX, Carles y POSNER, Daniel, "Capital social y democracia", Revista Española de Ciencia Política, 2, ISSN 1575-6548, pp 159-185 
(2006) CHAMBERS, Simone y KOPSTEIN, Jeffrey, "Civil Society and the State". En John S. Dryzek, Bonnie Honig y Anne Phillips (eds.), The Oxford Handbook of Political Theory, Oxford University Press, Oxford y Nueva York, pp 374-381

(1992) COHEN, Jean L. y ARATO, Andrew, Civil Society and Political Theory, The MIT Press, Cambridge y Londres

(1994) DUBIEL, Helmut, "Metamorfosis de la sociedad civil: Autolimitación y modernización reflexiva”, Debats, 50, ISSN 0212-0585, pp 109-123

(2008) DVOŘÁKOVÁ, Vladimíra, "Civil Society in Latin America and Eastern Europe: Reinvention or Imposition?", International Political Science Review, XXIX, 5, ISSN 0192-5121, pp 579-594

(2004) EDWARDS, Michael, Civil Society, Polity Press, Cambridge

(1996) FOLEY, Michael W. y EDWARDS, Bob, "The Paradox of Civil Society", Journal of Democracy, VII, 3, ISSN 1045-5736, pp 38-52

(1999) FOLEY, Michael W. y EDWARDS, Bob, "Is It Time to Disinvest in Social Capital?", Journal of Public Policy, XIX, 2, ISSN 1469-7815, pp 141-173

(1981) HABERMAS, Jürgen, Teoría de la acción comunicativa, II. Crítica de la razón funcionalista, (Ed. 1992), Ed. Taurus, Madrid

(1992) HABERMAS, Jürgen, Faktizität und Geltung. Beiträge zur Diskurstheorie des Rechts und des demokratischen Rechtsstaats, (Ed. 1994), Suhrkamp Verlag, Frankfurt am Main

(1996) HABERMAS, Jürgen, “Una consideración genealógica acerca del contenido cognitivo de la moral". En Jürgen Habermas, La inclusión del otro. Estudios de teoría política, (Ed. 1999), Ed. Paidós, Barcelona, pp 29-78

(1995) HALL, John A., "In Search of Civil Society". En John A. Hall (ed.), Civil Society. Theory, History, Comparison, Polity Press, Cambridge, pp 1-31

(2005) IBARRA, Pedro, Manual de sociedad civil y movimientos sociales, Ed. Síntesis, Madrid

(1988) KEANE, John, Democracia y sociedad civil, (Ed. 1992), Ed. Alianza, Madrid

(1996) LEVI, "Social and Unsocial Capital: A Review Essay of Robert Putnam's Making Democracy Work”, Politics \& Society, XXIV, 1, ISSN 0032-3292, pp 4555

(2001) NEWTON, Kenneth, "Trust, Social Capital, Civil Society, and Democracy", International Political Science Review, XXII, 2, ISSN 0192-5121, pp 201-214

(1995) PÉREZ-DÍAZ, Víctor, "The Possibility of Civil Society: Traditions, Character and Challenges". En John A. Hall (ed.), Civil Society. Theory, History, Comparison, Polity Press, Cambridge, pp 80-109 
(1993) PUTNAM, Robert D., Making democracy Work: Civic Traditions in Modern Italy, Princeton University Press, Nueva Jersey

(1996) RÖDEL, Ulrich, „Vom Nutzen des Konzepts der Zivilgesellschaft“, Zeitschrift für Politikwissenschaft, VI, 3, ISSN 1430-6387, pp 669-677

(1994) ROSENBLUM, Nancy L., "Civil Societies: Liberalism and the Moral Uses of Pluralism", Social Research, VI, 13, ISSN 0037-783X, pp 539-562

(1840) TOCQUEVILLE, Alexis de, La democracia en América, 2, (Ed. 2002), Ed. Alianza, Madrid

(1996) VALLESPÍN, Fernando, "Sociedad civil y 'crisis de la política", Isegoría, 3, ISSN 1130-2097, pp 39-58

(1997), VALLESPÍN, Fernando, “¿Reconciliación a través del Derecho? Apostillas a Facticidad y Validez de Jürgen Habermas". En José Antonio Gimbernat (ed.), La Filosofía Moral y Política de Jürgen Habermas, Biblioteca Nueva, Madrid, pp 199-223

(1990) WALZER, Michael, "The Civil Society Argument". En Chantal Mouffe (ed.), Dimensions of Radical Democracy. Pluralism, Citizenship, Community, Verso Publishing, Londres y Nueva York, pp 89-107 